DOI 10. 18307/2018. 0614

(C) 2018 by Journal of Lake Sciences

\title{
峡谷分层型水源水库表层沉积物溶解性有机物光谱特征"
}

\author{
王晓江 ${ }^{1,2}$, 黄廷林 ${ }^{1,2 * *}$, 李 楠 ${ }^{1,2}$, 周石磊 ${ }^{1,2}$, 李 扬 ${ }^{1,2}$, 张海涵 ${ }^{1,2}$,任梦甜 ${ }^{1,2}$ \\ ( 1 : 西安建筑科技大学,陕西省环境工程重点实验室,西安 710055) \\ (2:西安建筑科技大学,西北水资源与环境生态教育部重点实验室,西安 710055)
}

摘 要: 结合三维苂光光谱技术 (EEMs) 与紫外吸收光谱 (UV-vis), 并利用平行因子分析 (PARAFAC) 的方法, 对金盆水 库表层沉积物中溶解性有机质 (DOM) 光谱的空间分布特征及来源进行分析, 并探讨沉积物 DOM 的苂光组分与可溶性有 机氮 (SON)、可溶性无机氮 (SIN) 之间的相关性. 结果表明,金盆水库表层沉积物 DOM 由 3 类菼光组分组成, 分别是类富 里酸 $\mathrm{C} 1(235 \mathrm{~nm}, 315 \mathrm{~nm} / 430 \mathrm{~nm})$ 、类色氨酸 $\mathrm{C} 2(220 \mathrm{~nm}, 275 \mathrm{~nm} / 330 \mathrm{~nm})$ 和类胡敏酸 $\mathrm{C} 3(265 \mathrm{~nm} / 520 \mathrm{~nm})$, 各组分苂光 强度占总荧光强度百分比的平均值分别为 $43.15 \%$ 、31.54\% 和 $25.31 \%$. 表层沉积物 DOM 浓度在空间上呈现从上游到主库 区先减少后增加的趋势. 光谱斜率 $S_{275-295} 、 S_{350-400}$ 和光谱斜率比 $S_{\mathrm{R}}$ 反映出各采样点陆源与内源占比的差异性. 苂光指 数、自生源指标和腐殖化指标都表明金盆水库沉积物 DOM 的来源具有内源与陆源双重特征. 相关性分析表明,表层沉积 物 DOM 各组分与 SON 和 SIN 均呈显著正相关, 说明 DOM 与氮元素的迁移转化密切相关.

关键词: 金盆水库;表层沉积物;溶解性有机物;三维苂光光谱;紫外吸收光谱;平行因子分析

\section{Spectral characteristics of dissolved organic matter in the surface sediments from a can- yon-shaped, stratified, water-source reservoir}

\author{
WANG Xiaojiang ${ }^{1,2}$, HUANG Tinglin ${ }^{1,2 * *}$, LI Nan ${ }^{1,2}$, ZHOU Shilei ${ }^{1,2}$, LI Yang ${ }^{1,2}$, ZHANG Haihan ${ }^{1,2}$ \& \\ REN Mengtian ${ }^{1,2}$ \\ (1: Shanxi Key Laboratory of Environmental Engineering, Xi'an University of Architecture and Technology, Xi'an 710055, \\ P.R.China) \\ (2: Key Laboratory of Northwest Water Resource, Environment and Ecology, MOE, Xi'an University of Architecture and \\ Technology, Xi'an 710055, P.R.China)
}

\begin{abstract}
The distribution characteristics and sources of dissolved organic matter (DOM) in surface sediments of Jinpen Reservoir were investigated using fluorescence ultraviolet-visible ( UV-vis) and excitation-emission matrix spectra combined with parallel analysis (EEMs-PARAFAC). The correlation between source of DOM and soluble organic or soluble inorganic nitrogen was explored. The results showed that three fluorescent components were identified by PARAFAC model in surface sediments of Jinpen Reservoir, including fulvic-like component ( C1: $235 \mathrm{~nm}, 315 \mathrm{~nm} / 430 \mathrm{~nm}$ ), protein-like (C2: $220 \mathrm{~nm}, 275 \mathrm{~nm} / 330 \mathrm{~nm})$ and humic-like ( C3: $265 \mathrm{~nm} / 520 \mathrm{~nm}$ ). The relative proportions of C1, C2 and C3 were $43.15 \%, 31.54 \%$ and $25.31 \%$, respectively. DOM showed spatial distribution characteristics, which first decreased then increased from upstream to the reservoir area. The spectral slop $\left(S_{275-295}, S_{350-400}\right)$ and the spectral slope ratio $\left(S_{\mathrm{R}}\right)$ could be used to distinguish the difference in endogenesis and terrigenous component from different sampling sites. Based on the fluorescence index, biological index and humification index, the DOM of sediments exhibited both endogenous and terrigenous contribution in Jinpen Reservoir. Meanwhile, the fluorescence intensity had significantly correlation with soluble organic and soluble inorganic nitrogen, and DOM was closely related to the migration and transformation of nitrogen in sediments.
\end{abstract}

Keywords: Jinpen Reservoir; surface sediments; dissolved organic matter; EEMs; UV-vis; PARAFAC

* 国家自然科学基金项目 (51478378) 资助. 2017-12-13 收稿; 2018-03-19 收修改稿. 王晓江( 1989 ), 男, 硕士研 究生; E-mail: wxjang@126.com.

** 通信作者; E-mail: huangtinglin@ xauat.edu.cn. 
溶解性有机质 (dissolved organic matter,DOM) 是湖泊生态系统的重要组成部分之一,一般包括类腐殖 质、类蛋白质以及碳水化合物等, 是土壤、沉积物和水体中化学组成和结构十分复杂的有机混合物, 其主要 来源于水体和沉积物中动物与植物及微生物的降解 ${ }^{[1-2]}$. DOM 在生态系统物质和能量循环中起到非常重要 的作用, 是异氧微生物碳源和能源的主要提供者 ${ }^{[3]}$, 同时 DOM 还能与有机或无机环境污染物发生化学反 应, 从而导致其迁移转化、稳定性和生物可利用性等发生变化,进而改变其潜在生态风险 ${ }^{[4]}$.

近年来, 大量学者利用三维苂光光谱法一平行因子分析法 (EEMs-PARAFAC), 并结合紫外一可见光谱特 征, 分析了河流以及湖泊中溶解性有机质组分、结构及污染物迁移转化规律, 并解析溶解性有机质的来源、 分布特征及生物活动 ${ }^{[5]}$. 如张海威等 ${ }^{[6]}$ 利用三维荧光光谱法一平行因子分析法对新疆艾比湖主要人湖河流 精河与博尔塔拉河进行研究,并分析苂光指数与氮元素的相关性; 沈炼等 ${ }^{[7]}$ 利用紫外一可见吸收光谱和三维 苂光光谱技术对南汁河不同排污口表层沉积物进行研究, 分析出不同排污口的污染物来源; 程杰等 ${ }^{[8]}$ 利用 三维苂光光谱和紫外一可见光谱结合的方法探究了洱海沉积物溶解性有机氮的来源和空间分布特征; 冯可 心等 ${ }^{[9]}$ 利用 EEMs-PARAFAC 研究了丹江口水库表层沉积物可溶性有机物苂光组分、空间分布特征和来源, 以及不同组分苂光强度与氮磷等污染物的相关性. 对于作为水源的湖泊水库, 沉积物 DOM 的含量和性质对 于饮用水水质有重要的影响. 然而, 目前对于深水水源水库沉积物的 DOM 光谱特征的研究鲜有报道. 由于 深水水库具有明显的分层现象, 底层水体处于厌氧高还原环境, 沉积物中的 DOM 易从底泥释放到水体中, 尤其是一些含氮有机物的释放,造成水体富营养化 ${ }^{[10]}$. 因此, 通过对沉积物 DOM 光谱特征的分析, 以及探 索 DOM 和沉积物中氮素的互作关系,有助于对水体富营养化控制机理的研究.

黑河金盆水库是西安市主要的供水水源, 其水质安全极其重要. 由于金盆水库是一个深水型峡谷水库, 对水库沉积物的 DOM 研究, 有助于对水库沉积物和水体的微生物代谢和物质迁移转变有个更深层次的认 识. 特别在水体热分层时期, 水库沉积物作为水体污染源, 研究沉积物 DOM 特征有助于探索水库的污染物 的相关迁移转化. 本文主要应用 EEMs-PARAFAC 和紫外一可见吸收光谱技术研究处于热分层初期的金盆水 库 DOM 光谱特征, 以揭示金盆水库沉积物 DOM 的分布规律和化学行为, 以期为金盆水库的生态环境保护 提供理论基础和科学依据, 同时也为金盆水库水环境模型的构建和水体、沉积物之间的迁移转化提供数据 支撑,对进一步改善提高黑河金盆水库水质具有重要意义.

\section{1 材料与方法}

\section{1 研究区域概况}

黑河金盆水库 $\left(33^{\circ} 58^{\prime} \sim 34^{\circ} 3^{\prime} \mathrm{N}, 108^{\circ} 9^{\prime} \sim 108^{\circ} 13^{\prime} \mathrm{E}\right)$ 位于陕西省西安市周至县境内, 距黑河峪口大约 1.5 $\mathrm{km}$, 是西安市黑河引水系统的主要水源地. 水库距西安市 $86 \mathrm{~km}, 2002$ 年建成供水, 总库容 2 亿 $\mathrm{m}^{3}$, 年调节水 量 4.28 亿 $\mathrm{m}^{3}$, 其中城市供水占 $71.2 \%$ 为 3.05 亿 $\mathrm{m}^{3}$, 日平均供水量 80 万 $\mathrm{m}^{3}$, 供水保证率 $95 \%$, 是一座以城市 供水为主, 有防洪、发电、灌溉等综合效益的大型水利枢纽工程.

黑河流域属暖温带半干燥、半湿润大陆性气候, 气温差别较大, 流域植被良好, 河水清澈, 泥沙主要为推 移质, 河流悬移质含沙量小. 全流域面积 $2258 \mathrm{~km}^{2}$, 流域内森林覆盖率可达 $70 \%$, 黑峪口以上为峪谷山区, 平 均高程 (以海拔计) 为 $1850 \mathrm{~m}$, 分水线平均高程为 $2400 \mathrm{~m}$, 集水面积占全流域的 $65 \%$, 干流总长 $91.2 \mathrm{~km}$. 黑 河金盆水库属于大水深峡谷型水库, 四周植被覆盖, 径流大, 造成氮磷有机质等污染物富集, 沉积于库底, 使 沉积物颗粒中污染物含量不断增加,对水库水质造成影响.

\section{2 样品采集及处理}

根据金盆水库上游及库区的地貌和水力学特征, 沿着 “河流区一过渡区一主库区” ${ }^{[11-14]}$ 共设置 12 个采 样点 (S1 S12, 图 1). 其中 $\mathrm{S} 1$ ( 水深 $2.0 \mathrm{~m}$ ) 位于河流汇人口, 其河道狭窄, 坡度较大, 水流较快, 代表河流区; $\mathrm{S} 2$ (水深 $5.6 \mathrm{~m}$ ) 、S3(水深 $15.0 \mathrm{~m}$ )、 $\mathrm{S} 4$ ( 水深 $30.3 \mathrm{~m}$ )、 $\mathrm{S} 5$ (水深 $50.2 \mathrm{~m}$ )、S6(水深 $65.9 \mathrm{~m}$ ) 则分布在过渡区, 坡 度减少, 流速较缓; $\mathrm{S} 7$ (水深 $66.2 \mathrm{~m}$ ) 、 $\mathrm{S} 8$ (水深 $69.3 \mathrm{~m}$ ) 、 $\mathrm{S} 9$ (水深 $68.3 \mathrm{~m}$ )、 $\mathrm{S} 10$ (水深 $73.3 \mathrm{~m}$ ) 为主库区点, 水 面开阔, 水深最深, 流速最慢, $\mathrm{S} 10$ 靠近引水塔. $\mathrm{S} 11$ ( 水深 $36.2 \mathrm{~m}$ ) 为主库区靠近岸边的浅水区, $\mathrm{S} 12$ (水深 $72.1 \mathrm{~m}$ ) 位于小寒峪沟与主库区交界处. 2017 年 4 月 12 日,金盆水库处于热分层初期, 从上游到主库区 12 个采样点 (所有采样点均采用 GPS 定位), 用柱状采样器采集各样点的表层沉积物 $(0 \sim 2 \mathrm{~cm})$ 样品 ${ }^{[15]}$, 每个 
样点采集 3 个平行样. 新鲜样品采集后装于聚乙烯 封口袋中并编号, 放人冷藏箱带回实验室用冷冻干 燥机进行冷冻干燥, 并将干燥后的沉积物样品研磨 过 $100(0.149 \mathrm{~mm})$ 目篮. 称取 $2 \mathrm{~g}$ 研磨后的沉积物 样品, 加人 $40 \mathrm{ml}$ Milli-Q 超纯水混合进行 DOM 提 取 ${ }^{[16]}$, 振荡 $24 \mathrm{~h}\left(220\right.$ 转 $\left./ \min , 25^{\circ} \mathrm{C}\right)$ 后离心 $(6000$ 转 $/ \mathrm{min}, 15 \mathrm{~min})$, 取上清液过 $0.45 \mu \mathrm{m}$ 滤膜 (Whatman GF/F, 预先 $450^{\circ} \mathrm{C}$ 灼烧) 过滤后进行分 析. 对沿程各点位水体进行原位测定, 测定指标见 表 1 .

\section{3 沉积物碳、氮含量测定}

沉积物 DOM 浸提液用于测定 DOC 含量, 用于 表征 DOM 含量 ${ }^{[7]}$. DOC 含量采用总有机碳分析仪 (岛津 TOC, 日本) 高温燃烧法测定, 每个样品重复 测定 3 次, 保证测定结果变异系数 $<2 \%$. 干燥过筛 后的沉积物浸提液, 用于测定可溶性总氮 (STN)、 硝态氮和氨氮, 可溶性总氮与可溶性无机氮 ( SIN) (硝态氮与氨氮之和) 含量之差即为可溶性有机氮 ( $\mathrm{SON})$ 含量 ${ }^{[17]}$.

\subsection{DOM 吸收光谱分析}

沉积物 DOM 紫外一可见吸收光谱由紫外一可 见分光光度计 (UV-2450, 岛津) 测定, 扫描波长范 围为 $200 \sim 700 \mathrm{~nm}$, 步长为 $1 \mathrm{~nm}$, Milli- $Q$ 超纯水为参 比,中速扫描. 采用如下公式计算和校正后的吸收 系数 ${ }^{[18]}$ :

$$
a(\lambda)=2.303 \cdot D(\lambda) / r-a(700) \cdot \lambda / 700
$$

式中, $\lambda$ 为波长 $(\mathrm{nm}) ; D(\lambda)$ 为波长 $\lambda$ 处的吸光度; $a(\lambda)$ 为经过散射校正后的波长 $\lambda$ 处的吸收系数 $\left(\mathrm{m}^{-1}\right) ; r$ 为光程路径 $(\mathrm{m})$.

DOM 吸收光谱从紫外到可见波长随波长的增 加大致呈现指数衰减规律, 用如下公式表示 ${ }^{[19]}$ :

$$
a(\lambda)=a\left(\lambda_{0}\right) \exp \left[S\left(\lambda_{0}-\lambda\right)\right]
$$

式中, $\lambda_{0}$ 为参照波长 $(\mathrm{nm})$,一般选取 $440 \mathrm{~nm} ; S$ 为 指数函数曲线光谱斜率 $\left(\mu \mathrm{m}^{-1}\right)$; 本研究采用最小 二乘法对短波段 275 295 nm 和长波段 350 400 $\mathrm{nm}$ 之间的波段进行拟合, 得到光谱斜率 $S_{275-295}$ 和 $S_{350-400}$, 两者比值等于光谱斜率比 $S_{\mathrm{R}}$.

\section{5 三维荧光光谱分析}

沉积物 DOM 的三维荧光光谱采用日立苂光分

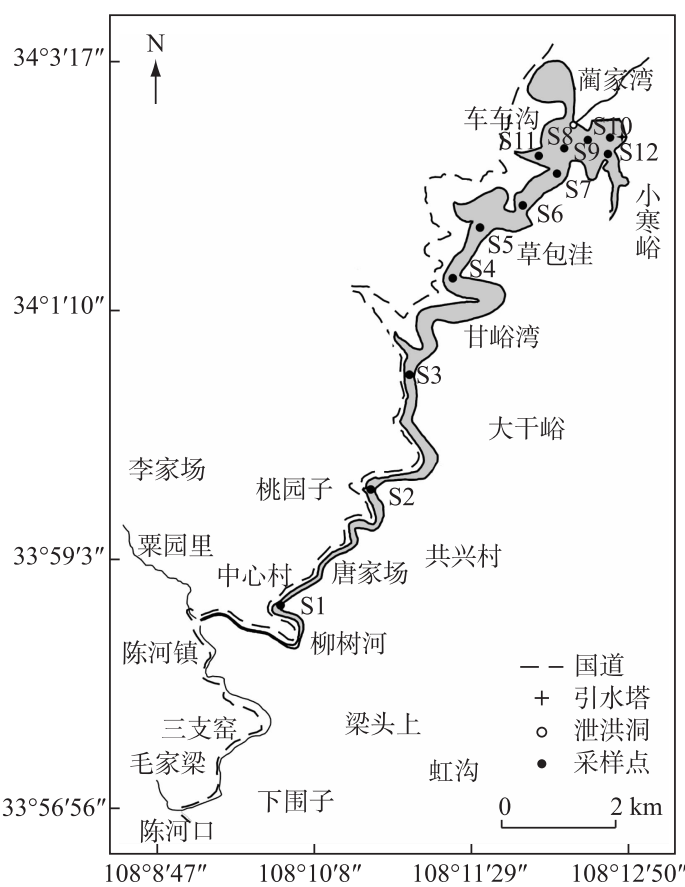

图 1 金盆水库采样点位置

Fig.1 Location of sampling sites in Jinpen Reservoir

表 1 金盆水库采样点水体的基本性质

Tab. 1 Basic characteristics of water of

\begin{tabular}{|c|c|c|c|c|c|}
\hline $\begin{array}{c}\text { 采样 } \\
\text { 点 }\end{array}$ & $\begin{array}{c}\text { 表层叶绿素 a/ } \\
(\mu \mathrm{g} / \mathrm{L})\end{array}$ & $\begin{array}{c}\text { 底部叶绿素 a/ } \\
(\mu \mathrm{g} / \mathrm{L})\end{array}$ & $\begin{array}{l}\text { 浊度/ } \\
\text { NTU }\end{array}$ & $\begin{array}{l}\text { 溶解氧/ } \\
(\mathrm{mg} / \mathrm{L})\end{array}$ & $\begin{array}{l}\mathrm{pH} \\
\text { 值 }\end{array}$ \\
\hline $\mathrm{S} 1$ & 2.33 & 4.92 & 35.3 & 10.80 & 7.69 \\
\hline S2 & 2.02 & 3.85 & 26.6 & 11.03 & 7.96 \\
\hline S3 & 2.23 & 2.02 & 21.9 & 11.10 & 7.91 \\
\hline $\mathrm{S} 4$ & 1.98 & 2.33 & 15.7 & 9.23 & 7.64 \\
\hline S5 & 1.85 & 2.89 & 8.6 & 7.91 & 7.67 \\
\hline S6 & 2.08 & 3.56 & 5.6 & 7.07 & 7.68 \\
\hline S7 & 2.43 & 4.82 & 6.8 & 7.06 & 7.73 \\
\hline $\mathrm{S} 8$ & 2.05 & 5.35 & 5.6 & 7.25 & 7.72 \\
\hline S9 & 2.66 & 5.89 & 5.1 & 6.11 & 7.98 \\
\hline $\mathrm{S} 10$ & 2.21 & 5.39 & 7.3 & 5.78 & 7.69 \\
\hline S11 & 3.68 & 8.65 & 3.6 & 8.68 & 7.51 \\
\hline $\mathrm{S} 12$ & 2.17 & 5.50 & 6.8 & 5.73 & 7.54 \\
\hline
\end{tabular}
sampling sites in Jinpen Reservior 光光度计 F-7000 测定, 配以 $1 \mathrm{~cm}$ 石英比色典, 仪器光源为 $150 \mathrm{~W}$ 氙灯, PMT 电压设为 $500 \mathrm{~V}$, 波长误差 \pm 1 $\mathrm{nm}$, 其中激发和发射单色仪的狭㖓跨度都为 $5 \mathrm{~nm}$, 扫描光谱进行仪器自动校正. 激发波长 $(E \mathrm{x})$ 范围从 200 $450 \mathrm{~nm}$, 波长间隔为 $5 \mathrm{~nm}$; 发射波长 $(E \mathrm{~m})$ 范围为 $250 \sim 600 \mathrm{~nm}$, 波长间隔为 $1 \mathrm{~nm}$, 扫描速度为 $2400 \mathrm{~nm} / \mathrm{min}$. 测定结果扣除 Mili-Q 超纯水三维荧光数据并进行 Delaunnay 三角形内插值法修正去除拉曼峰散射和瑞利散 射 $^{[20]}$. 利用 MATLAB 2016a 软件把 12 个样品的苂光矩阵组合, 采用 N-way 和 DOMFluor 工具箱进行平行因 
子分析. 参照 Stedmon 等 ${ }^{[21]}$ 的教程, 通过一致性分析确定苂光组分数,利用折半分析来分析结果的可靠性.

\section{6 数据统计分析}

实验数据采用 Excel 2007 软件进行统计分析; 利用 SPSS 22 软件进行相关性分析, 置信度设为 0.05 ; 光 谱斜率 $S$ 通过 Origin 9.0 软件进行线性拟合; 三维苂光光谱和 PARAFAC 模型模拟均在 Matlab2016a 软件中 进行分析处理; 多组数据显著性差异采用单因素方差分析,显著性检验采用独立样本 $T$ 检验.

\section{2 结果与讨论}

\section{1 沉积物 DOM 荧光组分特征分析}

利用 PARAFAC 模型对金盆水库沉积物中 DOM 的三维苂光光谱矩阵数据进行分析, 表层沉积物 DOM 中主要解析出 3 个荧光组分 (图 2, 表 2), 分别为 C1 ( $235 \mathrm{~nm}, 315 \mathrm{~nm} / 430 \mathrm{~nm}$ )、C2 (220 nm, $275 \mathrm{~nm} / 330 \mathrm{~nm}$ )
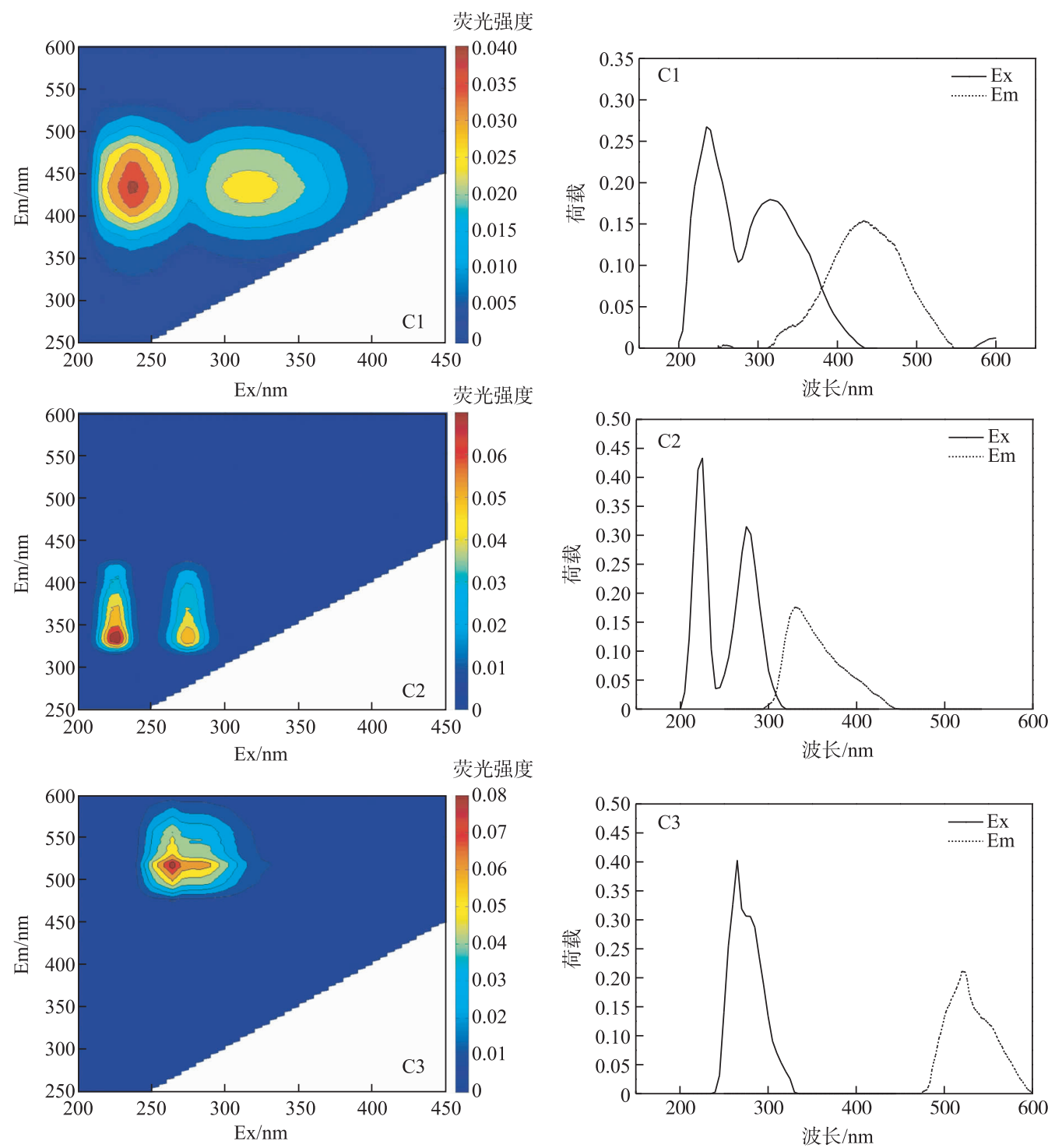

图 2 PARAFAC 解析出金盆水库沉积物的三个苂光组分及其激发发射波长位置

Fig.2 Fluorescence spectra of three previously identified PARAFAC components in sediments of Jinpen Reservoirs 
和 C3(265 nm/520 nm). C1 有 2 个激发峰和 1 个发射峰, 分别对应苂光峰 A 和 C, 代表陆源类腐殖质中的类 富里酸, 主要来源于森林、湿地 ${ }^{[22-23]}$. C2 同样有 2 个激发峰和 1 个发射峰, 分别对应荧光峰 $\mathrm{T} 2$ 和 $\mathrm{T} 1$, 代表类 蛋白组分中的类色氨酸基团, $\mathrm{T} 2$ 为低激发区类色氨酸, $\mathrm{T} 1$ 为高激发区类色氨酸,其主要游离或结合在蛋白 质中, 通常来源于水中浮游植物和微生物等残体的降解 ${ }^{[2-25]}$. C3 反映了长波类腐殖质的菼光特性, 代表类 胡敏酸,属于陆源类腐殖质,其芳香性大于类富里酸,主要来源为高等植物腐解的有机物 ${ }^{[26]}$.

表 2 沉积物中 3 个苂光组分特征及来源分析

Tab.2 Fluorescence characteristics and source analysis of the three fluorescent components in sediments

\begin{tabular}{|c|c|c|c|c|}
\hline 组分 & $\mathrm{Ex} / \mathrm{Em} / \mathrm{nm}$ & 物质 & 主要来源 & 参考文献中物质对应的波长 \\
\hline C1 & $235,315 / 430$ & 类富里酸质 & 陆源类, 土壤有机质 & $250 \mathrm{~nm}, 320 \mathrm{~nm} / 400 \mathrm{~nm}^{[27]} ; 310 \sim 360 \mathrm{~nm} / 370 \sim 450 \mathrm{~nm}^{[28]}$ \\
\hline $\mathrm{C} 2$ & $220,275 / 330$ & 类色氨酸 & 自生源类,藻类、生物降解 & $225 \mathrm{~nm}, 275 \mathrm{~nm} / 342 \mathrm{~nm}^{[29]} ; 270 \sim 280 / 320 \sim 350 \mathrm{~nm}^{[30]}$ \\
\hline C3 3 & $265 / 520$ & 类胡敏酸 & 陆源类,生物降解,陆生植物 & $265 \mathrm{~nm} / 525 \mathrm{~nm}^{[31]}$ \\
\hline
\end{tabular}

\section{2 苂光组分分布特征分析}

一定程度上,总苂光强度可以用来表征 DOM 浓度的高低. 通过研究对金盆水库沿程 12 采样点的总荧 光强度图 (图 3) 发现, 各组分苂光强度与总苂光强度空间分布趋势一致,从上游到主库区表层沉积物呈现先 降低再升高的趋势. 表层沉积物中 C1 组分苂光强度变化范围为 $2471.1 \sim 4860.0$ R. U./g, 平均值为 $4025.7 \pm$ 112.2 R.U. $/ \mathrm{g}(P<0.05)$, 所占比例达 $43.15 \%$; C2 组分苂光强度变化范围为 $2327.2 \sim 3021.0$ R.U. $/ \mathrm{g}$, 平均值为 2942.6 \pm 80.6 R.U. $/ \mathrm{g}(P<0.05)$, 所占比例达 $31.54 \%$;C3 组分苂光强度变化范围为 $2255.4 \sim 2550.4$ R.U. $/ \mathrm{g}$, 平 均值为 $2360.5 \pm 75.5$ R.U. $/ g(P<0.05)$, 所占比例达 $25.31 \%$. 相比较而言, 类蛋白 C1 组分 (类富里酸) 占比例 最大, 腐殖质 $\mathrm{C} 2$ 组分 (类色氨酸) 次之, 腐殖质 $\mathrm{C} 3$ 组分 (类胡敏酸) 最弱. 类腐殖质由径流携带的部分腐殖 质以及内源浮游动植物释放的有机物经过细菌进一步降解后产生, 类蛋白主要由微生物及水生生物新陈代 谢作用产生 ${ }^{[32]}$. Kritiansen 等 $^{[33]}$ 研究发现腐殖质类 DOM 在好氧条件下易被氧化降解, 转化为分子量更小, 也更易被微生物所吸收利用的碳源. 总苂光强度从上游 S1 (河流区) 到 S6 (人库口) 呈现下降趋势, 其原因是 水库周围被植被覆盖, 降雨冲刷地表, 形成的径流携带的营养性土壤逐渐沉降, 从柳树河流进的营养性污染 物随着深度的增加浓度逐渐降低, DOM 浓度也随之降低. 水流从人库区流人主库区时, 断面突然拓宽, 流速 减慢, 并且受到水库水流顶托的影响, 泥沙逐渐淤泥 ${ }^{[34]}$, DOM 浓度逐渐升高. 并且水面拓宽, 易于藻类繁殖, 造成蛋白类 DOM 升高. S11 点各苂光强度都较小, 可能是因为 S11 点处于主库区浅水处, 营养性土壤颗粒在 此处沉降较少, 并且微生物 (包括藻类) 活动较强, 蛋白类 DOM 占比较高, 与表 1 中原位测定的表层水体叶 绿素及底部水体叶绿素、溶解氧、浊度和 $\mathrm{pH}$ 值的情况相吻合.

- 1 1
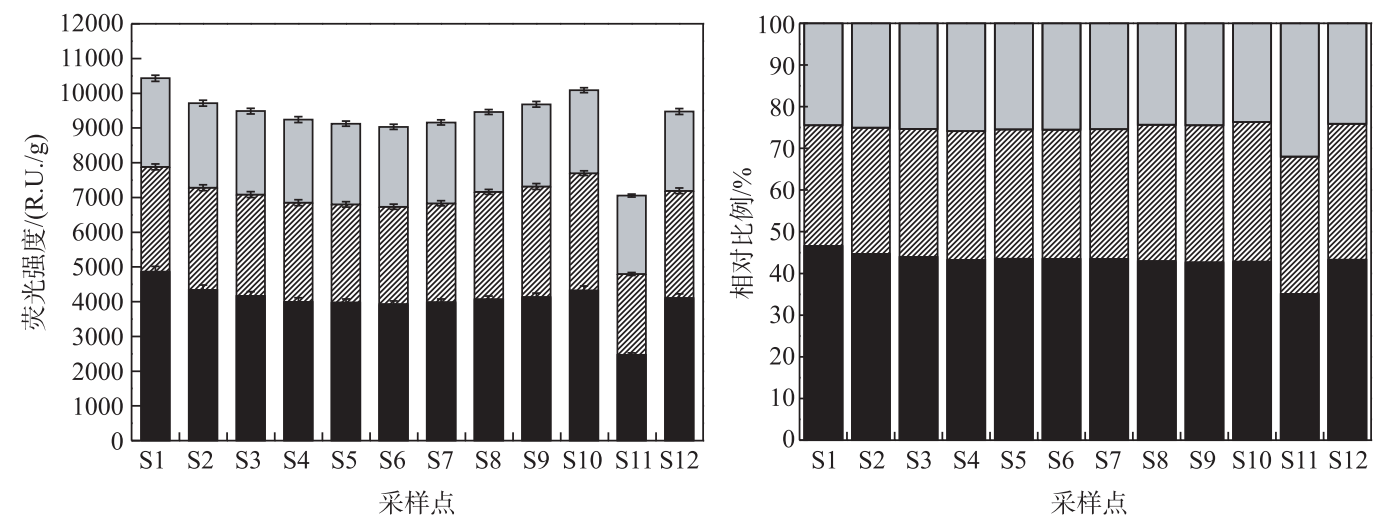

图 3 金盆水库 DOM 苂光组分相对比例

Fig.3 Relative proportions of DOM fluorescent components in Jinpen Reservior 


\section{3 荧光特征指数及差异性分析}

苂光指数 $(F I)$ 是 $\mathrm{Ex}=370 \mathrm{~nm}$ 时, $\mathrm{Em}$ 在 470 和 $520 \mathrm{~nm}$ 处的苂光强度比值 ${ }^{[35]}$, 被用于表征 DOM 中腐殖 质组分的来源. 通常认为, $F I>1.9$ 时, 主要源于水体自身微生物活动, 自生源特征相对明显; $F I<1.3$ 时主要为 陆地和土壤输人为主, 水体和自生源贡献较少 ${ }^{[36]}$. 内源多由水体中浮游动植物和沉积物微生物的降解和分 泌物产生, 表现为类蛋白物质占主要成分 ${ }^{[37]}$. 陆源则主要来自流域内土壤、森林以及人类活动等造成有机 质的输人, 表现为类腐殖质为主 ${ }^{[38]}$. 本研究中, 金盆水库 $F I$ 的范围为 $1.62 \sim 1.88$, 平均值为 1.72 , 由于金盆水 库流域内植被覆盖较好, 且人为活动较少, 陆源输人可能来源于降雨径流携带的陆生植物和土壤营养有机 质,内源 DOM 可能来源于藻类和细菌的胞外释放,因此金盆水库 DOM 是混合来源.

腐殖化指标 $(H I X)$ 是 $\mathrm{Ex}=254 \mathrm{~nm}$ 时, $\mathrm{Em}$ 在 435 480 nm 苂光强度积分值和 300 345 nm 菼光积分值之 比 $^{[39]}$, 通常认为 $H I X$ 越高, 表示 DOM 腐殖化程度越高 ${ }^{[00]}$, 有机质越稳定. 有研究表明 ${ }^{[41]}, H I X>16$ 代表 DOM 具有强腐殖化特征, 以陆源输人为主; $10<H I X<16$ 代表较强腐殖化特征, 微弱自生源特征, 陆源输人明显; $6<H I X<10$ 代表较强腐殖化特征, 且有较弱自生源特征; $4<H I X<6$ 代表弱腐殖化特征, 及较强自生源特征; $H I X<4$ 表示为自生源. 金盆水库 $H I X$ 变化范围为 3.76 7.37, 平均值为 6.03 , 大于 6 , 说明属于较强腐殖化特 征,中度自生源.

自生源指标 $(B I X)$ 是 $\mathrm{Ex}=310 \mathrm{~nm}$ 时, $\mathrm{Em}$ 在 380 和 $430 \mathrm{~nm}$ 处的菼光强度比值 ${ }^{[42]}$, 反映水体自生源的相 对贡献, $B I X$ 值较高表示 DOM 以浮游植物和细菌的有机体降解产物等内源为主 ${ }^{[43]}$. 有研究认为 $B I X$ 在 $0.8 \sim$ 1.0 之间, 表示样本中存在新生的自生源 DOM 较多; 而 $0.6 \sim 0.8$ 之间表示自生源贡献较少 ${ }^{[4]}$, 金盆水库沉积 物 $B I X$ 指数 $0.5 \sim 0.81$, 平均值 0.73 , 表明其 DOM 为中度新近自生源特征, $\mathrm{S} 11$ 为较强新生自生源特征.

结合国内外不同地区 DOM 的苂光特征指数对比发现 (表 3), 对于沿岸以森林生态系统为主, 人为干扰 小的湖泊 DOM (如大洪湖、Lumpen 和 Albufera des Grau 等), 其 $F I$ 值均较低, 而 $H I X$ 值较高, 表明水体 DOM 输人以腐殖化程度较高的陆源输人占主导. 而城镇河流水库 (如南汁河和周村水库), 受工业农业废水、生活 污水排放等人为因素的影响, $F I$ 和 $B I X$ 值较高, 表明自生源 DOM 占主导. 与水体相比, 沉积物的 $F I$ 值普遍 大于水体, 表明在这些区域水体 DOM 来源中陆源占有较大比重, 沉积物 DOM 来源中自生源占有较大部分. 黑河金盆水库是典型的沿岸森林生态系统的深水峡谷型水库, DOM 输人既有水生植物和微生物等自生源特 征,也有地表径流陆源的补给.

表 3 不同研究 DOM 苂光特征参数比较

Tab.3 Comparison of fluorescence parameters for DOM samples from different studies

\begin{tabular}{|c|c|c|c|c|c|c|c|c|c|}
\hline \multirow{2}{*}{ 来源 } & \multirow{2}{*}{ 研究区域 } & \multicolumn{2}{|r|}{$F I$} & \multicolumn{2}{|r|}{$H I X$} & \multicolumn{2}{|r|}{$B I X$} & \multirow{2}{*}{ 湖泊特征 } & \multirow{2}{*}{$\begin{array}{l}\text { 参考 } \\
\text { 文献 }\end{array}$} \\
\hline & & 平均值 & 范围 & 平均值 & 范围 & 平均值 & 范围 & & \\
\hline \multirow[t]{8}{*}{ 水体 } & Albufera des Grau & 1.39 & - & 8.93 & - & 0.63 & - & 森林 & {$[45]$} \\
\hline & 长寿湖 & 1.61 & $1.57 \sim 1.67$ & 4.36 & $3.18 \sim 6.30$ & 0.83 & $0.81 \sim 0.87$ & 农田、林地 & {$[43]$} \\
\hline & 大洪湖 & 1.49 & $1.48 \sim 1.52$ & 34.95 & $15.24 \sim 68.44$ & 0.64 & $0.63 \sim 0.65$ & 森林 & {$[43]$} \\
\hline & Circului Lake & 1.25 & - & 1.87 & - & 0.96 & - & 城镇 & {$[46]$} \\
\hline & Morii Lake & 1.25 & - & 2.21 & - & 1.11 & - & 城镇 & {$[46]$} \\
\hline & Lumpen & 1.28 & - & - & - & - & - & 森林 & {$[47]$} \\
\hline & 周村水库 & 1.63 & $1.57 \sim 1.74$ & 1.3 & $1.18 \sim 1.40$ & 0.94 & $0.93 \sim 0.97$ & 城镇 & {$[48]$} \\
\hline & 太湖 & - & $1.54 \sim 1.96$ & - & - & - & - & 林地、城镇 & [49] \\
\hline \multirow[t]{5}{*}{ 沉积物 } & 艾比湖 & 1.80 & - & - & $1.10 \sim 1.90$ & - & $0.60 \sim 0.80$ & - & {$[6]$} \\
\hline & 南洞河 & 2.32 & $2.23 \sim 2.47$ & 4.96 & $3.87 \sim 8.71$ & 0.85 & $0.66 \sim 0.94$ & 城镇 & [7] \\
\hline & 乌梁素海 & - & $1.74 \sim 1.96$ & - & - & - & - & 农田、林地 & {$[50]$} \\
\hline & 丹江口水库 & 1.71 & $1.52 \sim 2.02$ & 3.72 & $0.22 \sim 7.68$ & 0.74 & $0.56 \sim 0.96$ & 城镇 & {$[10]$} \\
\hline & 金盆水库 & 1.72 & $1.62 \sim 1.88$ & 6.03 & $3.76 \sim 7.37$ & 0.73 & $0.50 \sim 0.81$ & 森林 & 本研究 \\
\hline
\end{tabular}

“一”表示文章中没有相关数据.

本研究对沉积物 DOM 中 3 个苂光峰分别作相关性分析 (表 4), 结果显示 C1、C2 和 C3 组分之间呈显著 
相关 $(P<0.01)$,表明 DOM 中类腐殖质和类蛋白可能存在同 源性,组分来源比较复杂. 总体来说, 金盆水库表层沉积物 DOM 来源既有内源输人又有陆源输人的双重特征, 苂光强 度分布差异性显著是由于营养性物质来源不同导致的.

周子振等 ${ }^{[51]}$ 研究发现金盆水库沉积物总氮含量为 $1252 \pm$ $101 \mathrm{mg} / \mathrm{kg}$, 总磷含量为 $769 \pm 24 \mathrm{mg} / \mathrm{kg}$, 沉积物污染程度处于 最低级级别 ${ }^{[52]}$, 不会出现严重内源污染现象. 金盆水库属于 大水深峡谷型水库, 森林植被覆盖率高, 两岸土壤腐殖质发 育程度高,春季降雨冲刷地表,造成径流携带大量有机质颗 粒, 后续的降解也成为 DOM 的主要来源之一. 由于金盆水库自身特征, 水文条件造成金盆水库沉积物 DOM 来源为混合输人,并且陆源输人特征明显.

\section{4 沉积物 DOM 吸收光谱分析}

本研究中采用波长 $350 \mathrm{~nm}$ 处的吸收系数来表征 DOM 浓度. 金盆水库表层沉积物吸收系数 $a_{350}$ 平均值 为 $20.92 \pm 1.96 \mathrm{~m}^{-1}$, 变化范围为 $10.55 \sim 26.31 \mathrm{~m}^{-1}$, 沉积物中 DOC 含量范围为 $313.65 \sim 687.23 \mathrm{mg} / \mathrm{kg}$, 平均值 为 $535.5 \pm 13.24 \mathrm{mg} / \mathrm{kg}$, STN 含量变化范围为 $201.98 \sim 306.74 \mathrm{mg} / \mathrm{kg}$, 平均值 $257.71 \pm 6.52 \mathrm{mg} / \mathrm{kg}$ (表 5 ). 通过 分析 $a_{350}$ 与沉积物指标的相关性, 可揭示 $a_{350}$ 与主要沉积物指标 DOC 和 STN 含量的相关性. 结果显示: 表层 沉积物溶解性有机质吸收系数 $a_{350}$ 与 DOC 和 STN 含量均存在显著正相关 $(P<0.01)$, 相关系数分别为 0.841 和 0.702 , 表明沉积物碳、氮指标可能与溶解性有机质有着相同的来源. Fighot 等 $^{[53]}$ 研究发现, 相比于紫外可 见吸收光谱的吸收值, 光谱斜率和光谱斜率比更能解释 DOM 的特性. 沈炼等 ${ }^{[7]}$ 在研究南淝河不同排口表层 沉积物 DOM 光谱特征时, 拟合了 $275 \sim 295$ 和 $350 \sim 400 \mathrm{~nm}$ 波段的斜率 $S$, 得出 $S_{275-295}$ 能够反映腐殖酸的变 化, 且 $S$ 值随腐殖质中陆源组分和内源组分比值的增加而减小. 金盆水库从上游到主库区 $S$ 值呈现先增加 后减小的趋势, 表明河流区和主库区表层沉积物 DOM 腐殖质中较多的来自陆地和土壤的 C1 组分. 光谱斜 率比 $S_{\mathrm{R}}$ 在各点差异不大, $\mathrm{S} 11$ 点的 $S_{\mathrm{R}}$ 值偏大, 原因是在浅水处微生物和藻类活动频繁, DOM 中自生源组分 占比较高, 与解析出来的菼光组分相一致.

表 5 金盆水库沉积物 DOM 中吸收光谱指数

Tab.5 The absorption spectrum index of DOM in the sediments of Jinpen Reservoir

\begin{tabular}{|c|c|c|c|c|c|c|c|}
\hline 采样点 & $\begin{array}{l}a_{350} / \\
\mathrm{m}^{-1}\end{array}$ & $\begin{array}{l}a_{440} / \\
\mathrm{m}^{-1}\end{array}$ & $\begin{array}{c}S_{275-295} / \\
\left(\times 10^{2} \mathrm{~nm}^{-1}\right)\end{array}$ & $\begin{array}{c}S_{350-400} \\
\left(\times 10^{2} \mathrm{~nm}^{-1}\right)\end{array}$ & $S_{\mathrm{R}}$ & $\begin{array}{c}\text { DOC/ } \\
(\mathrm{mg} / \mathrm{kg})\end{array}$ & $\begin{array}{c}\mathrm{STN} / \\
(\mathrm{mg} / \mathrm{kg})\end{array}$ \\
\hline $\mathrm{S} 1$ & 24.41 & 3.08 & 1.18 & 1.19 & 0.99 & 687.23 & 306.74 \\
\hline $\mathrm{S} 2$ & 22.30 & 2.92 & 1.19 & 1.26 & 0.95 & 572.12 & 274.27 \\
\hline S3 & 21.51 & 2.61 & 1.27 & 1.37 & 0.93 & 555.00 & 263.59 \\
\hline $\mathrm{S} 4$ & 19.23 & 2.69 & 1.35 & 1.49 & 0.90 & 442.12 & 249.23 \\
\hline $\mathrm{S} 5$ & 17.56 & 2.17 & 1.39 & 1.53 & 0.91 & 462.59 & 248.32 \\
\hline S6 & 17.24 & 2.48 & 1.45 & 1.61 & 0.90 & 523.98 & 247.45 \\
\hline S7 & 20.15 & 2.40 & 1.35 & 1.44 & 0.94 & 483.16 & 248.78 \\
\hline $\mathrm{S} 8$ & 22.24 & 2.55 & 1.28 & 1.33 & 0.96 & 523.56 & 256.42 \\
\hline S9 & 24.33 & 2.48 & 1.27 & 1.22 & 1.04 & 588.85 & 260.21 \\
\hline $\mathrm{S} 10$ & 26.31 & 3.54 & 1.19 & 1.11 & 1.07 & 677.26 & 272.25 \\
\hline $\mathrm{S} 11$ & 10.55 & 1.94 & 1.62 & 1.22 & 1.32 & 313.65 & 201.98 \\
\hline $\mathrm{S} 12$ & 25.19 & 3.31 & 1.26 & 1.29 & 0.98 & 596.48 & 263.23 \\
\hline
\end{tabular}

\section{5 沉积物各形态氮与荧光强度的相关分析}

土壤中的可溶性有机氮 $(\mathrm{SON})$ 能被直接释放出来 ${ }^{[54]}$, 且在特殊情况下, 藻类在吸收氮源时能更倾向于吸 收或直接吸收 SON 而不是溶解无机氮 $(\mathrm{SIN})^{[55]}$. 该研究沉积物中生物可利用较高的 SON 在交换态氮中占绝 对优势, 含量在 103.33 167.53 mg/ $\mathrm{kg}$ 之间,占可交换态总氮比例的 56.87\%, 而 SIN 含量在 98.65 139.21 mg/ 
$\mathrm{kg}$ 之间,占可交换态总氮比例的 43.13\% . 进一步通过沉积物 DOM 苂光组分与可交换态氮形态做回归分析 (图 4). 金盆水库表层沉积物 DOM 的 3 个组分的菼光强度与 SON 和 SIN 含量均呈显著正相关 $(P<0.01)$, 说 明沉积物 DOM 与氮元素的迁移转化密切相关, 同时说明 SIN 和 SON 含量受 DOM 各组分的影响, 尤其类腐 殖质的影响大. SON 含量与各组分的相关系数比 SIN 含量的更高, 说明沉积物 SON 更可能直接来源于微生 物对 DOM 中的降解. 这与丁咸庆 ${ }^{[56]}$ 研究亚热带典型森林土壤 SON 中, 得出土壤有机质的微生物降解是 SON 的重要来源的结论一致. 通过 DOM 的研究可以监测水库的 SON 演变特征, 为水库富营养化控制提供 技术支持.

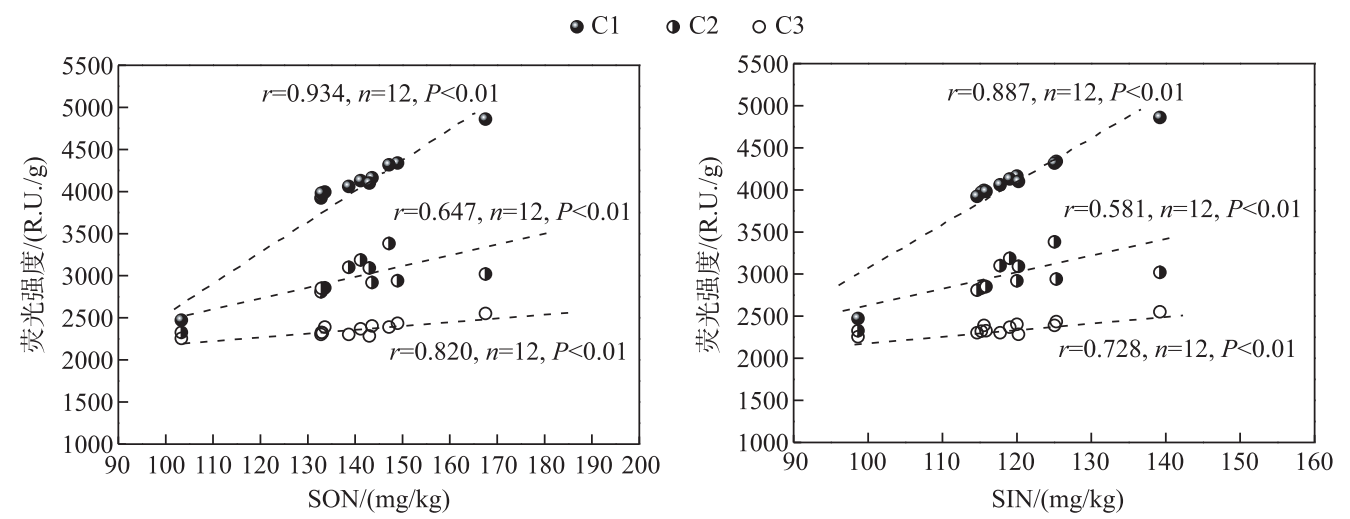

图 4 沉积物苂光强度与 SON 和 SIN 含量的相关性

Fig.4 Correlation between sediment fluorescence intensity and SON and SIN contents

\section{3 结论}

1 ) 通过平行因子分析得出金盆水库沉积物 DOM 样本中均存在 3 个荧光组分, 可分为类富里酸 ( 235 $\mathrm{nm}, 315 \mathrm{~nm} / 430 \mathrm{~nm})$ 、类色氨酸 $(220 \mathrm{~nm}, 275 \mathrm{~nm} / 330 \mathrm{~nm})$ 和类胡敏酸 $(265 \mathrm{~nm} / 520 \mathrm{~nm})$ 三类. 热分层初期 金盆水库主库区和河流区表层沉积物总苂光强度与过渡区相比较高, 总体呈现先降低后增加的趋势. 金盆 水库 DOM 样本中的 3 个组分具有同源性, 存在显著差异性 $(P<0.01)$, 并且表层沉积物 DOM 以类腐殖质 为主.

2 ) 通过各项苂光光谱指标 $(F I 、 B I X$ 和 $H I X)$ 的分析,综合得出热分层初期金盆水库表层沉积物 DOM 既 有内源又有陆源输人双重特征,其中陆源占比较大. 此特征源于水库自身特征和水文条件.

3 ) 通过对水库沉积物 DOM 吸收系数 $a_{350}$ 分析得出, 表层沉积物 DOM 浓度从上游到主库呈现规律性变 化, 且与水质指标具有同源性. 光谱斜率 $S_{275-295} 、 S_{350-400}$ 和光谱斜率比 $S_{\mathrm{R}}$ 沿程的变化规律表明, DOM 陆源组 分呈现先减少后增加的趋势, 这是由于水库自身地貌和水力特征, 从上游到下游有机颗粒逐渐沉积, 并在主 库区富集造成的.

4) 表层沉积物 DOM 各组分与 SON 和 SIN 含量均呈显著正相关 $(P<0.01)$, 与 SON 含量的相关性更显 著, 说明 DOM 与氮元素的迁移转化密切相关, 且 DOM 的降解是 SON 的重要来源之一.

\section{4 参考文献}

[ 1 ] Singh S, D'Sa EJ, Swenson EM. Chromophoric dissolved organic matter ( CDOM) variability in Barataria Basin using excitation-emission matrix (EEM) fluorescence and parallel factor analysis (PARAFAC). Science of the Total Environment, 2010, 408(16) : 3211-3222.

[ 2 ] Cory RM, Mc Knight DM. Fluorescence spectroscopy reveals ubiquitous presence of oxidized and reduced quinones in dissolved organic matter. Environmental Science \& Technology, 2005, 39(21) : 8142-8149.

[ 3 ] Ziegelgruber KL, Zeng T, Arnold WA et al. Sources and composition of sediment pore water dissolved organic matter in 
prairie pothole lakes. Limnology and Oceanography, 2013, 58(3): 1136-1146.

[ 4 ] Guo X, Yuan S, Li Q et al. Spectroscopic techniques for quantitative characterization of $\mathrm{Cu}$ ( II) and $\mathrm{Hg}$ ( II) complexation by dissolved organic matter from lake sediment in arid and semi-arid region. Ecotoxicology and Environmental Safety, 2012, 85(11): 144-150.

[ 5 ] Liu RX, Li B, Liu NN et al. Fluorescence characteristics of dissolved organic matter in freshwaters from Liaohe Basin and Midland of UK. Acta Scientiae Circumstantiae, 2014, 34(9): 2321-2328. [刘瑞霞, 李斌, 刘娜娜等. 辽河流域与英国 中部河湖水体中溶解有机质的苂光特性. 环境科学学报, 2014, 34(9) : 2321-2328.]

[ 6 ] Zhang HW, Zhang F, Li Z et al. Characteristics of three dimensional fluorescence spectra and its correlation with water quality in Jinghe and Bortala River from Lake Ebinur's major inflow tributaries, Xinjiang. J Lake Sci, 2017, 29(5): 1112-1120. DOI: 10.18307/2017.0509. [张海威, 张飞, 李哲等. 新疆艾比湖主要入湖河流精河与博尔塔拉河三维 苂光光谱特性及其与水质的关系. 湖泊科学, 2017, 29(5) : 1112-1120.]

[ 7 ] Shen S, Wang YL, Yang CM et al. Spectral characteristic of dissolved organic matter (DOM) in the surface sediments from different discharging points along the Nanfei River in Hefei City, Anhui Province. China Environmental Science, 2014, 34(9) : 2351-2361. [ 沈炼, 王育来, 杨长明等. 南淝河不同排口表层沉积物 DOM 光谱特征. 中国环境科学, $2014, \mathbf{3 4}(9): 2351-2361$.

[ 8 ] Cheng J, Zhang L, Wang SR et al. Spatial distribution and spectral characteristics of dissolved organic nitrogen with different molecular weight in Erhai sediment. Environmental Chemistry, 2014, 33(11) : 1848-1856. [程杰, 张莉, 王圣瑞等. 洱海沉积物不同分子量溶解性有机氮空间分布及光谱特征. 环境化学, 2014, 33(11) : 1848-1856.]

[ 9 ] Feng KX, Li YF, Jiang X et al. Distribution and source analysis of chromophoric dissolved organic matter of the surface sediments in the Danjiangkou Reservoir. Environmental Chemistry, 2016, 35(2): 373-382. [冯可心, 李永峰, 姜霞等. 丹江口水库表层沉积物有色可溶性有机物空间分布特征及其来源分析. 环境化学, 2016, 35(2): 373-382.]

[10］Yan CH. Studies on characteristics of dissolved organic matter and organic nitrogen in lake sediments [Dissertation]. Changsha: Hunan Agricultural University, 2011. [间彩虹. 湖泊沉积物溶解性有机质与有机氮特征研究 [ 学位论文]. 长 沙: 湖南农业大学, 2011.]

[11] Ahlfeld D, Joaquin A, Tobiason J. Case study: Impact of reservoir stratification on interflow travel time. Journal of Hydraulic Engineering, 2003, 129(12) : 966-975.

[12] Huang T, Li X, Rijnaarts $\mathrm{H}$ et al. Effects of storm runoff on the thermal regime and water quality of a deep, stratified reservoir in a temperate monsoon zone, in Northwest China. Science of the Total Environment, 2014, 485/486(3) : 820-827.

[13] Deng Y, Li J, Luo L et al. Temperature prediction model for reservoirs. Journal of Hydraulic Engineering, 2003, 7( 7) : 7-11. [邓云, 李嘉, 罗麟等. 水库温差异重流模型的研究. 水利学报, 2003, 7(7) : 7-11.]

[14] Lin GE, Wang T, Lin QQ. Spatial pattern and temporal dynamics of limnological variables in Liuxihe Reservoir, Guangdong. J Lake Sci, 2009, 21(3) : 387-394. DOI: 10.18307/2009.0312. [ 林国恩, 望甜, 林秋奇. 广东流溪河水库湖沼 学变量的时空动态特征. 湖泊科学, 2009, 21(3) : 387-394.]

[15] Chen JY, Wang SH, Jiang X et al. Fluorescence spectral characteristics of Fluorescent Dissolved Organic Matter (FDOM) in the surface sediments from Lihu Lake. Environmental Science, 2017, 38(1): 70-77. [ 陈俊伊, 王书航, 姜霞等. 蟙湖 表层沉积物若光溶解性有机质 (FDOM) 苂光光谱特征. 环境科学, 2017, 38(1): 70-77.]

[16] Bror OT. Dissolved organic matter characterization using multiway spectral decomposition of fluorescence landscape. Soil Science Society of America Journal, 2006, 70(6) : 2028-2037.

[17] Gao YW, Wang SR, Zhang WH et al. Seasonal variations of dissolved organic nitrogen in sediments of Lake Erhai. Research of Environmental Sciences, 2012, 25(6) : 659-665. [高悦文, 王圣瑞, 张伟华等. 洱海沉积物中溶解性有机氮 季节性变化. 环境科学研究, 2012, 25(6): 659-665.]

[18] Li SJ, Song KS, Zhao Y et al. Absorption characteristics of particulates and CDOM in water of Chagan Lake and Xinlicheng Reservoir in Autumn. Environmental Science, 2016, 37(1): 112-122. [李思佳, 宋开山, 赵荣等. 查干湖和新立 城水库秋季水体悬浮颗粒物和 CDOM 吸收特性. 环境科学, 2016, 37(1) : 112-122.]

[19] Bricaud A, Morel A, Prieur L. Absorption by dissolved organic matter of the sea (yellow substance) in the UV and visible Domains. Limnology and Oceanography, 1981, 26(1): 43-53.

[20] Zepp RG, Shelson WM, Moran MA. Dissolved organic fluorophores in southeastern US coastal waters: correction method for eliminating Rayleigh and Raman scattering peaks in excitation-emission matrices. Marine Chemistry, 2004, 89(1/2/3/ 
4) : 15-36.

[21] Stedmon CA, Markager S. Resolving the variability in dissolved organic matter fluorescence in a temperate estuary and its catchment using PARAFAC analysis. Limnology and Oceanography, 2005, 50(2) : 686-697.

[22] Coble PG. Characterization of marine and terrestrial DOM in seawater using excitation emission matrix spectroscopy. Marine Chemistry, 1996, 51(4) : 325-346.

[23] Leenheer JA, Nanny MA, Mclntyre C. Terpenoids as major precursors of dissolved organic matter in landfill leachates, surface water, and groundwater. Environmental Science and Technology, 2003, 37(11) : 2323-2331.

[24] Stedmon CA, Markager S, Bro R. Tracing dissolved organic matter in aquatic environments using a new approach to fluorescence spectroscopy. Marine Chemistry, 2003, 82(3/4) : 239-254.

[25] Zhang YL, Dijk MAV, Liu ML et al. The contribution of phytoplankton degradation to chromophoric dissolved organic matter (CDOM) in eutrophic shallow lakes: field and experimental evidence. Water Research, 2009, 43(18) : 4685-4697.

[26] Zsolnay A, Baigar E, Jimenez M et al. Differentiating with fluorescence spectroscopy the sources of dissolved organic matter in soils subjected to drying. Chemosphere, 1999, 38(1) : 45-50.

[27] Cai WL, Xu XY, Du X et al. Parallel factor analysis with EEM on dissolved organic matter in Chongqing section of Jialing River. Research of Environmental Sciences, 2012, 25(3): 276-281. [蔡文良, 许晓毅, 杜涃等. 嘉陵江重庆段 DOM 三 维苂光光谱的平行因子分析. 环境科学研究, 2012, 25(3): 276-281.]

[28] Fu PQ. Dissolved organic matter in natural aquatic environments and its complexations with metal ions: A study based on fluorescence spectroscopy[Dissertation]. Guangzhou: Institute of Geochemistry, Chinese Academy of Sciences, 2004. [傅 平青. 水环境中的溶解有机质及其与金属离子的相互作用——荧光光谱学研究 [学位论文]. 广州: 中国科学院地 球化学研究所, 2004.]

[29] Guo WD, Huang JP, Hong HS et al. Resolving excitation emission matrix spectroscopy of estuarine CDOM with parallel factor analysis and its application in organic pollution monitoring. Environmental Science, 2010, 31(6): 1419-1427. [ 郭 卫东, 黄建平, 洪华生等. 河口区溶解有机物三维苂光光谱的平行因子分析及其示踪特性. 环境科学, 2010,31 (6) : 1419-1427.]

[30] Brogi SR, Gonnelli M, Vestri S et al. Biophysical processes affecting DOM dynamics at the Arno river mouth (Tyrrhenian Sea). Biophysical Chemistry, 2015, 197: 1-9.

[31] Cheng QL, Zheng BH, Wang SR et al. Optical signatures of chromophoric dissolved organic matter in water body of Tien Lake. Spectroscopy and Spectral Analysis, 2014, 34(3): 698-703. [程庆霖, 郑丙辉, 王圣瑞等. 滇池水体有色溶解性 有机质 (CDOM) 三维荧光光谱特征. 光谱学与光谱分析, 2014, 34(3) : 698-703.]

[32] Rochelle-Newall EJ, Fisher TR. Production of chromophoric dissolved organic matter fluorescence in marine and estuarine environments: an investigation into the role of phytoplankton. Marine Chemistry, 2002, 77(1) : 7-21.

[33] Kristensen E, Ahmed SI, Devol AH. Aerobic and anaerobic decomposition of organic matter in marine sediment: Which is fastest? Limnology and Oceanography, 1995, 40(8) : 1430-1437.

[34] Lu SY, Xu MS, Jin XS et al. Pollution characteristics and evaluation of nitrogen, phosphorus and organic matter in surface sediments of Lake Changshouhu in Chongqin, China. Environmental Science, 2012, 33(2): 393-398. [卢少勇, 许梦爽, 金相灿等. 长寿湖表层沉积物氮磷和有机质污染特征及评价. 环境科学, 2012, 33(2): 393-398.]

[35] Fellman JB, Hood E, Spencer RGM. Fluorescence spectroscopy opens new windows into dissolved organic matter dynamics in freshwater ecosystems: A review. Limnology and Oceanography, 2010, 55(6) : 2452-2462.

[36] Mc Knight DM, Boyer EW, Westerhoff PK et al. Spectrofluorometric characterization of dissolved organic matter for indication of precursor organic material and aromaticity. Limnology and Oceanography, 2001, 46(1) : 38-48.

[37] Miller M, Mcknight M. Comparison of seasonal changes in fluorescent dissolved organic matter among aquatic lake and stream sites in the Green Lakes Valley. Journal of Geophysical Research, 2010, 115(12): 1-12.

[38] Cai MH, Xiao YH, Wang F et al. Retrieving the origin and transformation history of dissolved organic matter in the surface sediment from an Arctic fjord (Kongsfjorden, Svalbard). Oceanologica Sinica, 2012, 34(6): 102-113. [ 蔡明红, 肖宜 华, 王峰等. 北极孔斯峡湾表层沉积物中溶解有机质的来源与转化历史. 海洋学报, 2012, 34(6) : 102-113.]

[39] Cheng YY, Wang SL, Hu SB et al. The fluorescence characteristics of dissolved organic matter (DOM) in the sea grass ecosystem from Hainan by fluorescence excitation-emission matrix spectroscopy. Spectroscopy and Spectral Analysis, 2015, 35(1) : 141-145. [程远月, 王帅龙, 胡水波等. 海草生态系中 DOM 的三维菼光光谱特征. 光谱学与光谱分析, 
$2015,35(1): 141-145$. ]

[40] Ohno T, Fernandez IJ, Hiradate S et al. Effects of soil acidification and forest type on water soluble soil organic matter properties. Geoderma, 2007, 40(1/2): 176-187.

[41] Huguet A, Vacher L, Relexans S et al. Properties of fluorescent dissolved organic matter in the Gironde Estuary. Organic Geochemistry, 2009, 40(6): 706-719.

[42] Chen XF, Chuai XM, Liu T et al. Characteristics and source identification of the dissolved organic matter in lakes of west Jiangsu by spectroscopy. J Lake Sci, 2012, 24(2) : 259-266. DOI: 10.18307/2012.0214. [ 陈小锋, 揣小明, 刘涛等. 江 苏省西部湖泊溶解性有机物光谱学特征和来源解析. 湖泊科学, 2012, 24(2): 259-266.]

[43] Lu S, Jiang T, Zhang JZ et al. Three-dimensional fluorescence characteristic differences of dissolved organic matter (DOM) from two typical reservoirs. China Environmental Science, 2015, 35(2) : 516-523. [卢松, 江蹈, 张进忠等. 两 个水库型湖泊中溶解性有机质三维苂光特征差异. 中国环境科学, 2015, 35(2) : 516-523.]

[44] Huguet A, Vacher L, Relexans S et al. Properties of fluorescent dissolved organic matter in the Gironde Estuary. Organic Geochemistry, 2009, 40(6) : 706-719.

[45] Catal NN, Obrador B, Felip M et al. Higher reactivity of allochthonous vs. autochthonous DOC sources in a shallow lake. Aquatic Science, 2013, 75(4) : 581-593.

[46] Ghervase L, Ioja C, Carstea EM et al. Spectroscopic and physico-chemical evaluation of lentic ecosystems from Bucharest City. Environmental Problems and Development, 2010: 272-277.

[47] Kothawala DN, von Wachenfeldt E, Koehler B et al. Selective loss and preservation of lake water dissolved organic matter fluorescence during long-term dark incubations. Science of the Total Environment, 2012, 433 : 238-246.

[48] Huang TL, Fang KK, Zhang CH et al. Optical characteristics differences of dissolved organic matter from two different full mixed reservoirs in winter based on UV-vis and EEMs. Environmental Science, 2016, 37(12): 4577-4585. [黄廷林, 方 开凯, 张春华等. 利用 UV-vis 及 EEMs 对比冬季完全混合下两个不同特征水库溶解性有机物的光学特性. 环境科 学, 2016, 37(12): 4577-4585.]

[49] Song XN, Yu T, Zhang Y et al. Distribution characterization and source analysis of dissolved organic matter in Taihu Lake using a three dimensional fluorescence excitation emission matrix. Acta Scientiae Circumstantiae, 2010, 30(11) : 23212331. [ 宋晓娜, 于涛, 张远等. 利用三维苂光技术分析太湖水体溶解性有机质的分布特征及来源. 环境科学学报, 2010, 30(11): 2321-2331.]

[50] Feng WY, Jiao LX, Zhang S et al. Spectral characteristics of dissolved organic matter in the sediments of Wuliangsuhai Lake. China Environmental Science, 2013, 33(6): 1068-1074. [冯伟莹, 焦立新, 张生等. 乌梁素海沉积物溶解性有 机质荧光光谱特性. 中国环境科学, 2013, 33(6) : 1068-1074.]

[51] Zhou Z, Huang T, Li Y et al. Sediment pollution characteristics and in situ control in a deep drinking water reservoir. Journal of Environmental Sciences, 2016, DOI: 10.1016/j.jes.2016.05.006.

[52] Huang TL, Liu F, Shi JC. Distribution characteristics and pollution status evaluation of sediments nutrients in a drinking water reservoir. Environmental Science, 2016,37(1) : 166-172. [黄廷林, 刘飞, 史建超. 水源水库沉积物中营养元素 分布特征与污染评价. 环境科学, 2016, 37(1): 166-172.]

[53] Fighot GG, Benner R. A novel method to estimate DOC concentrations from CDOM absorption coefficients in coastal waters. Geophysical Research Letters, 2011, 38(3): 1-5.

[54] Shao XH, Houba VJG, Hu AT et al. Release kinetics of soluble organic nitrogen from soil. Journal of Nanjing Agricultural University, 1990, 13(3) : 65-69. [郡孝候, Houba VJG, 胡䨠堂等. 土壤可溶性有机态氮的释放动力学研究. 南京 农业大学学报, 1990, 13(3): 65-69.]

[55] Chen WX, Wang ZH. Potential impact of different forms of nitrogen on algal-bloom in eutrophic water body. Water and Wastewater Engineering, 2008, 34(9) : 22-27. [ 陈文煊, 王志红. 不同形态氮对富营养化水源藻华暴发的潜在影响. 给水排水, 2008, 34(9): 22-27.]

[56] Ding XQ. Characteristics of soil organic nitrogen, soluble and dissolved organic nitrogen ( SON/DON) in typical subtropical forests [Dissertation]. Changsha: Central South University of Forestry \& Technology, 2016. [丁咸庆. 亚热带典型森 林土壤有机氮、可溶性和溶解性有机氮 (SON/DON) 特征研究 [学位论文]. 长沙: 中南林业科技大学, 2016. ] 